\title{
A Systematic Review of Usefulness Design Goals of Occupational mHealth Apps for Healthcare Workers.
}

\author{
Nurha Yingta \\ Jose Abdelnour Nocera \\ University of West London \\ Ikram Ur Rehman \\ Obed Brew \\ University of West London \\ St. Mary's Road, Ealing, UK \\ University of West London \\ University of West London \\ St. Mary's Road, Ealing, UK \\ St. Mary's Road, Ealing, UK \\ St. Mary's Road, Ealing,UK \\ 21363511@student.uwl.ac.uk Jose.Abdelnour-Nocera@uwl.ac.uk Ikram.Rehman@uwl.ac.uk Obed.Brew@uwl.ac.uk
}

\begin{abstract}
To improve healthcare professionals health and wellbeing at work, many available effective treatments including meditation, and workplace intervention, have been developed. However, the utilisation of these interventions is still limited. Currently, various mobile health applications (mHealth Apps) exist to assist a wide range of users with different occupational health issues, such as stress, anxiety, and burnout. Despite their advantages, post-download uptake of mHealth apps by end-users remains low. Some of the reasons for this are poor usability, irrelevant or missing user-desired features, and poor user experience. This review paper explores the usefulness of mHealth Apps for the early detection of occupational-related ill-health among healthcare workers. To achieve this, we developed a conceptual framework that identifies relevant usability, utility, and user experience design goals that enhance the usefulness of such mHealth apps. This paper initially presents a systematic review of the literature that identifies design goals proven to be relevant or often lacking. The review shows that occupational mHealth apps rarely fit end users' backgrounds, work contexts, and dynamics. In turn, these identified design goals will be used as assessment points with end-users in subsequent stages of our project. Expected results at the end of the project will provide an enhanced understanding of usefulness design goals that contribute to the long-term use and adoption of these apps.
\end{abstract}

Keywords: mHealth Apps, Occupational ill-health, Usefulness, Usability, Utility, User Experience, Healthcare Workers

\section{INTRODUCTION}

Occupational ill-health is commonly associated with any physical and mental health conditions that cause as a result of organisational factors as well as an imbalance of demands, skills and social support at work. Workers in the medical sector are at increased risk of occupational-related ill-health due to the extraordinary stressors in this environment. Everyday stressors related to the healthcare profession include long work hours, dealing with pain, loss and emotional suffering, disease outbreak, and providing support to families (Liu et al., 2020). These stressors can trigger physical and mental health issues, such as stress, burnout and anxiety.

The COVID-19 pandemic has led to feelings of unhappiness, increased stress, burnout and anxiety, particularly among healthcare workers (HCWs) (Kinman, Teoh and Harriss, 2020). Many HCWs have experienced a high prevalence of emotional burnout, physical symptoms, and workrelated pressure (Barello, Palamenghi and
Graffigna, 2020). This is because the fear of transmitting COVID-19 could cause HCW to isolate from their families for months, causing the feeling of loneliness, anxiety, and depression (UK Parliament, 2020). Thus, it is crucial to design effective tools to help HCWs detect their occupational-related ill-health much earlier.

The emergence of mobile health applications (mHealth apps) allows user to be highly engaged in boosting health prevention and supporting the quality of life for doctors, nurses, and patients (Boudreaux et al., 2014). The term mHealth first became popular in the early 1990s when telecommunication systems and electronic processes were used for supporting healthcare practices for the first time (Dicianno et al., 2015). According to Marshall et al. (2020), an mHealth app is defined as an application program that offers health-related services through smartphones and tablets to fulfil health-specific purposes, such as stress management and prevention. Mediums for mHealth deployment are not only limited to mobile phone applications but extends to other mobile devices, such as body wearables and swallowed 
health monitors (Aryana, Brewster and AbdelnourNocera, 2018). The emergence of mHealth apps allows users to be highly engaged in boosting health prevention and improving the quality of life (QoL) for doctors, nurses, and other job workers (Boudreaux et al., 2014).

Despite their advantages, it remains a huge challenge to find effective mHealth apps to support occupational ill-health. Besides, not much has been done to identify and assess the factors impacting the usefulness and adoption in usability, user experience and utility. Human-Computer Interaction $(\mathrm{HCl})$ is concerned with understanding and designing human-centred interactive systems, where usability and user experience have been the most studied and applied concepts. Research on usefulness has been more limited (Nocera, Dunckley and Sharp, 2007; MacDonald and Atwood, 2014); therefore, conducting a systematic literature review of factors involved with usefulness design goals is a valuable undertaking. This review focuses on the usefulness design goals of mobile mHealth apps to support occupational ill-health in HCWs.

The paper's outline is as follows: Section 2 provides a brief review covering related fields of $\mathrm{HCl}$ research, including usefulness, usability, utility, and user experience. This is followed in section 3 by a description of the methods involved and review findings. The paper closes by highlighting key insights to facilitate the adoption and continued use of such mHealth apps.

\section{RELATED AREAS}

\subsection{Defining usefulness}

The usefulness of a system is a concept that has been defined and explored in different ways in disciplines such as Information System, $\mathrm{HCl}$ and IT (Nocera, Dunckley and Sharp, 2007). Several authors in previous studies have addressed the terms "usefulness" in different ways. For example, for Davis, usefulness is a perception of how a system enhances job performance or task completion (Davis, 1989). As Burns mentions in the context of ergonomics research, usefulness "requires that a design has the functionality required to accomplish work domain objectives" as opposed to just being easy to use (Burns et al., 1997).

Most of the research on mHealth has been focused on perceived usefulness and based on acceptance models such as the Technology Acceptance Model (TAM) and e-Commerce Acceptance Model (EAM) (Schnall et al., 2016; Alsswey and Al-Samarraie, 2020). For instance, Alsswey and Al-Samarraie (2020) use the TAM model to identify the factors impacting intention of use based on culture, which feeds into the system's perceived usefulness. A similar study was found in (Schnall et al., 2016), which uses the EAM to analyse the need for mHealth to be perceived as beneficial.

(Nielsen, 1994) defines a functional interactive system as compounded with the attribution of usability and utility. In addition to usability and utility, usefulness is influenced by the emotional feelings with a system, including enjoyment and trust to provide a richer experience of continued use (Lankton and Wilson, 2007; MacDonald and Atwood, 2014). Usefulness has also been defined as subject to interpretations grounded in the sociocultural spaces of both developers and users (Nocera, Dunckley and Sharp, 2007). Overall, the literature on usefulness reflects that this is a complex construct defined by usability, utility and user experience (UX) factors contingent on users' contexts and sociocultural backgrounds.

Designing useful mHealth apps is vital to HCW's adoption and continued use. Considering HCW's real-world experiences is essential to designing integrated and useful mHealth solutions (Aryana, Brewster and Abdelnour-Nocera, 2018). Therefore, to build useful mHealth apps, understanding usability, utility, and UX design goals must be considered when designing a new mobile design solution.

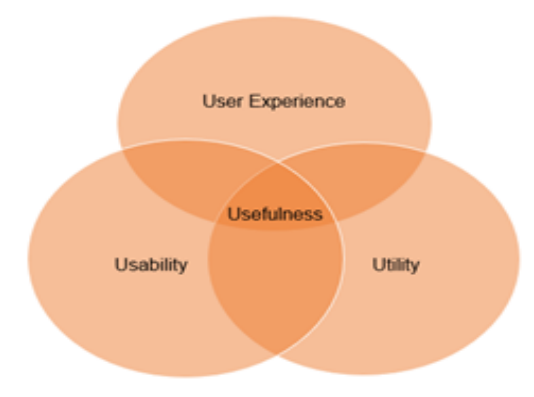

Figure 1 A Design-Driven Conceptual Framework for Occupational mHealth

The framework presented in Figure 1 summaries the types of goals for the usefulness of occupational mHealth apps in term of relevant usability, utility and user experience goals. These identified goals will be used as part of a questionnaire with healthcare workers in the context of a diary study of occupational mHealth app use.

\section{Review Methodology and Findings}

Four resources including ACM digital Library, IEEE Xplore, SAGE journal, and Google Scholar were considered without time limitation to identify relevant studies. The search terms relating to mHealth apps, "usefulness", "usability", "utility", and "healthcare workers" in different Boolean permutations were used to identify relevant 
literature. Studies that were not journal or full conference articles, such as editorials or comments, were excluded. 112 papers that review mHealth apps in the occupational contexts were initially identified, and after applying the exclusion criteria, 37 papers were included in the review. The papers were then read to identify relevant usability, utility, and user experience goals. The following inclusion criteria were considered in the screening process, as shown in Table 1. Papers that did not include all of the four criteria were excluded.

Table 1 Inclusion criteria

\begin{tabular}{|l|l|}
\hline NO & Inclusion criteria \\
\hline 1 & $\begin{array}{l}\text { Studies that use mobile health } \\
\text { application or mHealth apps }\end{array}$ \\
\hline 2 & $\begin{array}{l}\text { Studies relevant to usefulness, usability, } \\
\text { user experience, and utility. }\end{array}$ \\
\hline 3 & $\begin{array}{l}\text { Studies that use occupational related ill- } \\
\text { health or work-related ill-health or health }\end{array}$ \\
\hline 4 & $\begin{array}{l}\text { Studies that relevant to healthcare } \\
\text { workers or healthcare professionals }\end{array}$ \\
\hline
\end{tabular}

We cannot list all reviewed papers here due to space limitations of the position paper, but we have provided at least one reference for each goal.

Table 2. Identified usefulness goals of occupational mHealth apps

\begin{tabular}{|c|c|c|}
\hline $\begin{array}{l}\text { Usability } \\
\text { goals }\end{array}$ & Utility goals & $\begin{array}{l}\text { User experience } \\
\text { goals }\end{array}$ \\
\hline $\begin{array}{l}\text { Provide } \\
\text { contextually } \\
\text { relevant } \\
\text { information, } \\
\text { which is easy } \\
\text { to } \\
\text { understand } \\
\text { Healthcare } \\
\text { workers have } \\
\text { said apps } \\
\text { should reflect } \\
\text { their own work } \\
\text { domain } \\
\text { context and } \\
\text { roles. }\end{array}$ & $\begin{array}{l}\text { Support self- } \\
\text { help guidance } \\
\text { and in-depth } \\
\text { knowledge for } \\
\text { occupational } \\
\text { health and } \\
\text { wellbeing: } \\
\text { The reviewed } \\
\text { literature reveals } \\
\text { this as a feature } \\
\text { that is lacking or } \\
\text { not sufficiently } \\
\text { developed. }\end{array}$ & $\begin{array}{l}\text { Reinforce trust } \\
\text { and perceived } \\
\text { security in } \\
\text { mHealth apps: } \\
\text { It is necessary } \\
\text { for users to feel } \\
\text { confident that the } \\
\text { system will } \\
\text { behave as } \\
\text { intended. This } \\
\text { has resulted in } \\
\text { the degree of } \\
\text { collaboration with } \\
\text { the system } \\
\text { securely and } \\
\text { willingly. }\end{array}$ \\
\hline $\begin{array}{l}\text { Match user } \\
\text { expectations } \\
\text { about the } \\
\text { type of app: } \\
\text { prevention or } \\
\text { management } \\
\text { Help the user } \\
\text { access the } \\
\text { information } \\
\text { they need, } \\
\text { whether the } \\
\text { app helps } \\
\text { them prevent }\end{array}$ & $\begin{array}{l}\text { Promote social } \\
\text { connectedness. } \\
\text { The app should } \\
\text { include some } \\
\text { communication } \\
\text { and information } \\
\text { sharing features } \\
\text { such as a group } \\
\text { collaboration } \\
\text { among app users } \\
\text { and with clinicians }\end{array}$ & $\begin{array}{l}\text { Manage the } \\
\text { performance } \\
\text { expectancy of } \\
\text { mHealth apps: } \\
\text { The app design } \\
\text { should be } \\
\text { consistent with } \\
\text { its intended goal, } \\
\text { e.g. if it is } \\
\text { presented as a } \\
\text { prevention app } \\
\text { then its features } \\
\text { should be }\end{array}$ \\
\hline
\end{tabular}

\begin{tabular}{|c|c|c|}
\hline $\begin{array}{l}\text { or manage } \\
\text { work-related } \\
\text { ill-health. }\end{array}$ & & $\begin{array}{l}\text { consistent with } \\
\text { this aim. }\end{array}$ \\
\hline $\begin{array}{l}\text { Provide } \\
\text { simple } \\
\text { navigation } \\
\text { This goal has } \\
\text { been found to } \\
\text { increase } \\
\text { adoption in } \\
\text { workers with } \\
\text { intense } \\
\text { workload and } \\
\text { constant } \\
\text { interruptions. }\end{array}$ & $\begin{array}{l}\text { Notify users } \\
\text { about app } \\
\text { updates (e.g. app } \\
\text { changes) } \\
\text { Inform the user } \\
\text { when the app has } \\
\text { some changes or } \\
\text { updates. User } \\
\text { should be } \\
\text { informed about } \\
\text { important new } \\
\text { features }\end{array}$ & $\begin{array}{l}\text { App should be } \\
\text { perceived as } \\
\text { easy to use } \\
\text { This goal has } \\
\text { been found to } \\
\text { increase } \\
\text { adoption in } \\
\text { workers with } \\
\text { intense workload } \\
\text { and constant } \\
\text { interruptions. }\end{array}$ \\
\hline $\begin{array}{l}\text { Users need to } \\
\text { recover } \\
\text { easily from } \\
\text { errors } \\
\text { This goal has } \\
\text { been found to } \\
\text { increase } \\
\text { adoption in } \\
\text { workers with } \\
\text { intense } \\
\text { workload and } \\
\text { constant } \\
\text { interruptions. }\end{array}$ & $\begin{array}{l}\text { Gamifying app } \\
\text { tasks wherever } \\
\text { possible. } \\
\text { Gamification such } \\
\text { as points and } \\
\text { badges boosts } \\
\text { motivation and } \\
\text { keeps workouts } \\
\text { fun. }\end{array}$ & $\begin{array}{l}\text { App } \\
\text { engagement } \\
\text { should be } \\
\text { rewarded: the } \\
\text { user needs to } \\
\text { receive some } \\
\text { tokens such as } \\
\text { ribbons, coupons } \\
\text { or cashback in } \\
\text { return when } \\
\text { progressing } \\
\text { towards health } \\
\text { goals to keep an } \\
\text { emotional } \\
\text { connection. }\end{array}$ \\
\hline
\end{tabular}

In terms of usability goals, providing the contextually relevant information is frequently referred in the context of healthcare workers adoption and continued use of mhealth apps (Liew et al., 2019; Farao et al., 2020). Due to the fastpaced nature of healthcare work, this goal must be taken into consideration when designing mHealth apps. The app needs to display information related to healthcare worker's current tasks and work settings in order to deliver contextually relevant information. More importantly, designers or developers need to understand what content works best and how it should be implemented to increase the adoption and continued use of such apps. A future recommendation would be to implement a user-centred design in which the user will be able to express their work domain contexts and roles. This recommendation is in line with Coursaris and Kim (2011), who recommend designing an app that fits users' needs in a particular setting to improve system integrations, adoption, and loyalty.

Matching user expectations about the type of app and providing simple navigation are other commonly mentioned goals in the literature ( Bell et al., 2016: Vaghefi and Tulu, 2019). In the first instance, the app should clarify whether it is used to prevent or manage work-related ill-health. Providing users with the ability to choose what they need from a health perspective should be taken into account carefully. 
For example, the latter goal will be utilised in a context of frequent interruptions, multitasking, and increased workload, and poor navigation could cause dropout rates and continued use of such apps. Building simple navigation of such apps impacts increasing the adoption and download rates (e.g. Alqahtani and Orji, 2019).

Recovering easily from errors is another relevant usability goal, particularly when dealing with mobile health apps (Russ and Saleem, 2018; Liew et al., 2019). Due to the nature of the fast-paced environment, the fewer the errors, the more likely users will intend to adopt and continue using such apps (Sittig et al., 2020). The above review indicates that desired usability goals in occupational mHealth apps are primarily underpinned by pragmatic motivations rather than hedonic ones.

Utility goals also play an important role in enhancing the uptake of mHealth apps supporting a set of functions. The lack of desired features is seen as one of the reasons for abandoning such apps (Ventola, 2014). It has been proved that userdesired features play an important aspect in the adoption and continued use of such apps (Chandrashekar, 2018). Utility goals such as supporting health conditions, self-help guidance and in-depth knowledge (Collins et al., 2020) and promoting social connectedness (Chandrashekar, 2018) are seen as crucial by end-users.

Notifying users about app updates (Lapin, 2014) and gamifying app types have been found by (Peever et al., 2017) as lacking or underdeveloped among healthcare workers and other workers subjected to similar needs. Future occupational $\mathrm{mHealth}$ apps should be more integrated with these identified goals into those who work in clinical work environments or workplace where a high level of work-related ill-health is predominant (Collins et al., 2020).

It is worth observing that most of the UX goals identified in literatures are predominately driven by a reinforced trust in mHealth apps (Byambasuren, Beller and Glasziou, 2019) managing the performance expectancy of mHealth apps (Odendaal et al., 2015), perceived ease of use (Divall, Camosso-Stefinovic and Baker, 2013) and rewarding engagement (Helf et al., 2015). These experience goals are, as with usability goals, mainly of a pragmatic rather than hedonic nature. Within the identified studies, hedonic aspects seem to be less discussed goals in the design of mHealth apps.

Overall, It is advisable that future studies should further consider the exploration of user emotional experiences in the workplace and in particular for HCWs use in the clinical environment. This is consistent with previous studies (Christensen, Kjeldskov and Rasmussen, 2007; Mburu, Franz and Springer, 2013), which suggest that user emotional experiences directly relate to the usefulness of such apps. Thus, user emotional experiences might provide meaningful feedback for product design as well as enhance app adoption and continued use. It is essential to understand how UX at work evolves over time and the key reasons for changing UX. Clemmensen et al. (2020) found UX at work in greenhouse workers overtime to be ordinary. However, our intended research questions this and will assess whether experience in healthcare work is beyond ordinary.

\section{Conclusion}

The review presented in this paper provides insightful knowledge for the design of occupational mHealth apps to enhance users' experience in order to continue using such apps. Occupational ill-health is an important issue and calls for new mHealth tools to be explored. Due to the nature of healthcare professionals work contexts and environments, future occupational mHealth apps should be designed differently following domain-relevant and distinct design goals such as those identified in this review. More importantly, Understanding HCW experiences cognitive challenges and demands from the workplace contexts will ensure the design of relevant and useful occupational mHealth solutions. The proposed framework and goals address these aspects are contributions to the literature on mHealth by advancing knowledge on the usercentred design of this genre of apps, focusing on healthcare workers (Yen and Bakken, 2012; Torous et al., 2018).

\section{REFERENCES}

Alqahtani, F. and Orji, R. (2019) 'Usability Issues in Mental Health Applications', in. ACM, pp. 343348. doi: 10.1145/3314183.3323676.

Alsswey, A. and Al-Samarraie, H. (2020) 'Elderly users' acceptance of mHealth user interface (UI) design-based culture: the moderator role of age', Journal on multimodal user interfaces, 14(1), pp. 49-59. doi: 10.1007/s12193-019-00307-w.

Aryana, B., Brewster, L. and Abdelnour-Nocera, J. (2018) 'Design for mobile mental health: an exploratory review'. Available at: http://uwl.summon.serialssolutions.com/2.0.0/link/0/ eLvHCXMwIVxLSwMxEB5sT16komK1ylxFWrOvNu mtVBevRS97Ckl2FqS1gu3i3-

8kqSie7DkhGWZI5pvHNwBZOhLDP39CQqm0jcqd TYRNnJN1qqwjQ03RMMQluZ1SVousqnxPzf03Nc Ynzjdvvtw8ar9We3oVW4I81mv7UDAc6UAnE76Z6 yVfBAex- 
uUgyh6c7JEdzqlpTuGl1mcwfgwdEsjQEN8_LD9Bj NPOMRIQp2jWSKEPLPS7MVJJzkGUT6_z5yHfo6 MUG-

1HNP9lqv2Scbpdai9fdgFdjuTpEjBXTghWmUwMx1 VFY5yica0mQtaMA2rqw92 j706YO81HLOfD2Nc0 8kAutvPIm6Cqm6D2nYJdYWB.

Barello, S., Palamenghi, L. and Graffigna, G. (2020) 'Burnout and somatic symptoms among frontline healthcare professionals at the peak of the Italian COVID-19 pandemic', Psychiatry research, 290, p. 113129. doi:

10.1016/j.psychres.2020.113129.

Boudreaux, E. et al. (2014) 'Evaluating and selecting mobile health apps: strategies for healthcare providers and healthcare organizations', Translational Behavioral Medicine, 4(4), pp. 363371. doi: 10.1007/s13142-014-0293-9.

Burns, C. M. et al. (1997) 'Towards viable, useful and usable human factors design guidance', Applied ergonomics, 28(5), pp. 311-322. doi: 10.1016/S0003-6870(97)00012-4.

Byambasuren, O., Beller, E. and Glasziou, P. (2019) 'Current Knowledge and Adoption of Mobile Health Apps Among Australian General Practitioners: Survey Study', JMIR mHealth and uHealth, 7(6), pp. e13199-e13199. doi: 10.2196/13199.

Chandrashekar, P. (2018) 'Do mental health mobile apps work: evidence and recommendations for designing high-efficacy mental health mobile apps', mHealth, 4(Journal Article), pp. 6-6. doi: 10.21037/mhealth.2018.03.02.

Christensen, C., Kjeldskov, J. and Rasmussen, K. (2007) 'GeoHealth: a location-based service for nomadic home healthcare workers', in. ACM, pp. 273-281. doi: 10.1145/1324892.1324951.

Collins, D. A. J. et al. (2020) 'A Pilot Evaluation of a Smartphone Application for Workplace Depression', International journal of environmental research and public health, 17(18), p. 6753. doi: 10.3390/ijerph17186753.

Davis, F. D. (1989) 'Perceived Usefulness, Perceived Ease of Use, and User Acceptance of Information Technology', MIS quarterly, 13(3), pp. 319-340. doi: 10.2307/249008.

Dicianno, B. E. et al. (2015) 'Perspectives on the evolution of mobile (mHealth) technologies and application to rehabilitation', Physical therapy, 95(3), p. 397.
Divall, P., Camosso-Stefinovic, J. and Baker, R. (2013) 'The use of personal digital assistants in clinical decision making by health care professionals: A systematic review', Health informatics journal, 19(1), pp. 16-28. doi: $10.1177 / 1460458212446761$.

Farao, J. et al. (2020) 'A user-centred design framework for mHealth', PloS one, 15(8), p. e0237910. doi: 10.1371/journal.pone.0237910.

Helf, C. et al. (2015) 'mHealth Stakeholder Integration: A gamification-based Frameworkapproach towards behavioural change', in. ACM, pp. 268-274. doi: 10.1145/2837126.2837153.

Kinman, G., Teoh, K. and Harriss, A. (2020) 'Supporting the well-being of healthcare workers during and after COVID-19', Occupational medicine (Oxford, England), 70. doi: 10.1093/occmed/kqaa096.

Lankton, N. K. and Wilson, E. V. (2007) 'Factors Influencing Expectations of e-Health Services within a Direct-Effects Model of User Satisfaction', E-service journal, 5(2), pp. 85-112. doi: 10.2979/ESJ.2007.5.2.85.

Lapin, K. (2014) 'Deriving Usability Goals for Mobile Applications', in. ACM, pp. 1-6. doi: 10.1145/2643572.2643576.

Liew, M. S. et al. (2019) 'Usability Challenges for Health and Wellness Mobile Apps: Mixed-Methods Study Among mHealth Experts and Consumers', JMIR mHealth and uHealth, 7(1), p. e12160. doi: 10.2196/12160.

Liu, N. et al. (2020) 'Prevalence and predictors of PTSS during COVID-19 outbreak in China hardesthit areas: Gender differences matter', Psychiatry research, 287, p. 112921. doi: 10.1016/j.psychres.2020.112921.

MacDonald, C. and Atwood, M. (2014) 'What does it mean for a system to be useful?: an exploratory study of usefulness', in. ACM, pp. 885-894. doi: 10.1145/2598510.2598600.

Mburu, S., Franz, E. and Springer, T. (2013) 'A conceptual framework for designing mHealth solutions for developing countries', in. ACM, pp. 31-36. doi: 10.1145/2491148.2491154.

Nielsen, J. (1994) 'Usability inspection methods', in Conference companion on Human factors in computing systems, pp. 413-414.

Nocera, J. A., Dunckley, L. and Sharp, H. (2007) 'An Approach to the Evaluation of Usefulness as a 
Social Construct Using Technological Frames', International journal of human-computer interaction, 22(1-2), pp. 153-172. doi: 10.1207/s15327590ijhc2201-02_8.

Odendaal, W. et al. (2015) 'Healthcare workers' perceptions and experiences on using mHealth technologies to deliver primary healthcare services: a qualitative evidence synthesis', Cochrane database of systematic reviews, 2015(11). doi: 10.1002/14651858.CD011942.

Peever, N. et al. (2017) 'Understanding initial experiences with Mindmax, an mHealth app that draws on shared interests in sports and video games', in. ACM, pp. 438-442. doi:

10.1145/3152771.3156152.

Russ, A. L. and Saleem, J. J. (2018) 'Ten factors to consider when developing usability scenarios and tasks for health information technology', Journal of Biomedical Informatics, 78, pp. 123-133. doi: 10.1016/j.jbi.2018.01.001.

Schnall, R. et al. (2016) 'A user-centered model for designing consumer mobile health (mHealth) applications (apps)', Journal of biomedical informatics, 60(Journal Article), pp. 243-251. doi: 10.1016/j.jbi.2016.02.002.

Sittig, S. et al. (2020) 'Characteristics of and Factors Influencing College Nursing Students' Willingness to Utilize mHealth for Health Promotion', Computers, informatics, nursing: CIN, 38(5), pp. 246-255. doi: $10.1097 /$ CIN.0000000000000600.

Torous, J. et al. (2018) 'Clinical review of user engagement with mental health smartphone apps: evidence, theory and improvements', Evidencebased mental health, 21(3), pp. 116-119.

Vaghefi, I. and Tulu, B. (2019) 'The Continued Use of Mobile Health Apps: Insights From a Longitudinal Study', JMIR mHealth and uHealth, 7(8), pp. e12983-e12983. doi: 10.2196/12983.

Ventola, C. L. (2014) 'Mobile devices and apps for health care professionals: uses and benefits', $P \& T$ (Lawrenceville, N.J.), 39(5), pp. 356-364.

Yen, P.-Y. and Bakken, S. (2012) 'Review of health information technology usability study methodologies', Journal of the American Medical Informatics Association : JAMIA, 19(3), pp. 413422. doi: 10.1136/amiajnl-2010-000020. 